\title{
Clinical Patterns of Primary Dystonias among Hospitalized Patients in Baghdad and Kut in Iraq
}

\author{
Saadoun Al Ameer ${ }^{1}$, Samer Mohammed Saeed2, Bahaa Hassan³, Zaki Noah Hasan ${ }^{4}$ \\ ${ }^{1}$ Department of Medicine, Alzehraa Teaching Hospital, Kut, Iraq \\ ${ }^{2}$ Department of Neurology, Baghdad Teaching Hospital, Baghdad, Iraq \\ ${ }^{3}$ Department of Neurology, Alkhademiya Teaching Hospital, Baghdad, Iraq \\ ${ }^{4}$ Department of Medicine, Alkindy College of Medicine, Baghdad, Iraq \\ Email:zaki_nooh@yahoo.com
}

Received 28 September 2015; accepted 9 November 2015; published 13 November 2015

Copyright (C) 2015 by authors and Scientific Research Publishing Inc.

This work is licensed under the Creative Commons Attribution International License (CC BY). http://creativecommons.org/licenses/by/4.0/

cC) (i) Open Access

\begin{abstract}
Aim of study: This study was carried out to describe characteristics of 22 primary dystonic patients and their response to therapy. Patients and method: Twenty-two patients were entered into the study from Baghdad teaching hospital, Al-Kadhymia teaching hospital in Baghdad, privet nursery home teaching hospital in Baghdad, and Alzehraa teaching hospital in Kut south to Baghdad from January 2005 to January 2008. All cases were primary dystonia, secondary dystonia has been excluded from our study. Neuroimiging and slit Lampe examination have been done for all cases, L-Dopa in dose of $10 / \mathrm{mg} / \mathrm{kg} / \mathrm{day}$ for 2 weeks was giving for all patients. Type of study is a retrospective cohort study. All patients were followed in the outpatient clinics of the hospitals mentioned previously with frequent neurological examinations. Results: Out of 22 patients, 15 (68\%) patients were females, $7(32 \%)$ were males. According to descriptive classifications of dystonia by age of onset, fourteen patients (64\%) were of early onset and eight (36\%) being late onset (26 years and older). Three patients had generalized dystonia, 19 patients had focal dystonia \{11 (58\%) cases were cervical (TORTICOLIS) type, 5 (26\%) blepharospasm type and segmental (LIMBES) dystonia $3(16 \%)$ \}. All cases were given L-DOPA in dose 10/mg/kg for 2 weeks, only two cases shown clinical response for the drug inform of absence of abnormal movements and improve quality of life. Conclusion: Dystonia is rare; however, early onset dystonia are more common than late onset. Dystonia are more common in females than in males and focal dystonia is more common than generalized dystonia.
\end{abstract}

\section{Keywords}

L-, Baghdad, L-DOPA, Classifications, Dystonia

How to cite this paper: Al Ameer, S., Saeed, S.M., Hassan, B. and Hasan, Z.N. (2015) Clinical Patterns of Primary Dystonias among Hospitalized Patients in Baghdad and Kut in Iraq. World Journal of Neuroscience, 5, 358-363. 


\section{Introduction}

Dystonia is a progressive lifelong disabling movement disorder that causes sustained muscle contractions with repetitive twisting movements and abnormal postures of the trunk, neck, face, or arms and legs [1]. Its prevalence is estimated to be 30 per 100,000 populations [1] [2]. Primary generalized torsion dystonia usually begins in childhood and is linked to several genetic loci with penetrance of 30 to 40 percent and variable clinical expression. Primary focal dystonias are 10 times as common as generalized dystonia; focal dystonia nearly always occurs in adults and may involve the neck, face, or arm, whereas the leg is rarely involved [3]. The loci of a small number of incompletely penetrant autosomal dominant focal dystonias have been mapped including DYT6, DYT7, and DYT13 [4]. Mutations in the torsin A gene (at the DYT1 locus) have also been identified in occasional patients with adult-onset focal dystonia [5]. Cervical dystonia, also known as spasmodic torticollis, is the most common focal dystonia. Neck and shoulder pain occurs in 75 percent of cases [6] [7]. Cranial dystonia may involve the eyelids, jaw, vocal cords, face, tongue, platysma, or pharynx. It usually begins after the age of 40 years old. Blepharospasm is the most common cranial dystonia, causing an increased blink frequency, forced eye closure, or difficulty opening the eyes [8] [9].

The pathophysiology of dystonia lies in the basal ganglia, specifically related to putamen, even though the evidence for that is still not completely clear [10] [11]. A role for dopamine is suggested by the therapeutic benefit of levodopa in doparesponsive dystonia and levodopa associated dystonia in Parkinson's disease as well as dystonia produced by dopamine-receptor-blocking antipsychotic drugs and the frequent association of dystonia with parkinsonism [12] [13]. The cerebral cortex sensorimotor presentation of affected body parts is enlarged in patients with focal dystonia [14]-[18].

Therapeutic options for dystonia comprised chemodenervation with botulinum toxin injections for patients with focal or segmental dystonia, medical treatments for both types of dystonia and deep brain stimulation for patients with generalised dystonia [14]-[18].

The aim of this study was to assess the types of primary dystonia and the demographic features of these patients in group of patients attending 4 hospitals in Baghdad and Kut.

\section{Patients and Method}

A cross-sectional study including twenty-two cases with primary dystonia, fifteen patients were female and seven were male patients, their age ranges between 1 - 58 years old; the patients were admitted in Baghdad teaching hospital, Al-Kadhymia teaching hospital in Baghdad, privet nursery home teaching hospital in Baghdad, and Alzehraa teaching hospital in Kut south to Baghdad during the period between January 2005 to January 2008.

Secondary dystonia including drug induced, heredodegenerative diseases with known neuropath-logical features, and dystonia caused by acquired structural abnormalities, has been excluded from our study. Also Clinical exclusion criteria include history of possible etiologic factor, e.g., head trauma, peripheral trauma, encephalitis, drug exposure, toxin exposure, and perinatal anoxia. Also we exclude patients with neurological abnormalities, those with hemidystonia and abnormal brain imaging. The study was approved by scientific and ethical committee of Baghdad teaching hospital

All patients were evaluated with history taking and an examination to rule out secondary dystonia. Birth history, developmental history, medication intake, exposure to toxin, history of trauma, and family history were taken. All cases were done neuroimaging, slit Lampe examination, and given L-Dopa in dose 10/mg/kg for 2 weeks. magnetic resonance imaging (MRI) of the brain and laboratory testing for an underlying structural, degenerative, or metabolic disorder are indicated when there was features suggestive of other neurologic findings . Disease was considered early onset when the age of onset was [19] years and below and late onset above [19] years.

Statistical analysis was done using SSPS version 19; T test were used for comparison of two numerical results, p value less 0.05 was considered statically significant.

\section{Results}

Dystonia was seen in 15 females (86\%) and 7 males (32\%) as shown in Table 1.

Median age at diagnosis was 23, mean 26.1 and range from 1 year to 58 years. According to descriptive classifications of dystonia by age of onset, fourteen (64\%) where early onset and eight (36\%) being 26 years and older so early onset common than late onset, as shown in Table 2. 
Table 1. Male to female gender.

\begin{tabular}{ccc}
\hline Gender & Number & $\%$ \\
\hline Male & 7 & $32 \%$ \\
Female & 15 & $68 \%$ \\
Total & 22 & $100 \%$ \\
\hline
\end{tabular}

Table 2. Dystonia onset.

\begin{tabular}{ccccc}
\hline Dystonia onset & Male & Female & Number & Percentage \\
\hline <and $=$ 26 years old & 4 & 10 & 14 & $64 \%$ \\
$>$ 26 years old & 3 & 5 & 8 & $36 \%$ \\
P value & & & 0.005 & \\
\hline
\end{tabular}

Median age for those early onset dystonia is 13.1 and mean is 13.4 in range from 1 year to 26 years old, while for those with late onset mean is 46.3 years old and median 45.5 years old in range from 33 to 58 years old.

Age groups of the patients at time of diagnosis shows that nine patients were below 20 years of age groups, eight patients were between 21 - 45 years of age groups, and five patients age more than 45 years (see Table 3 ).

Time interval between onset of symptoms and diagnosis shows that only eight patients (36\%) where diagnosis to have dystonia less than one year from onset of disease symptoms, four (18\%) between 1 - 3 years, two (9\%) between 3 - 5 years, and eight (36\%) over 5 years as shown in Table 4.

Generalized dystonia was reported in three patients, there ages were 15, 16, 22 years old, one has positive family history. Focal dystonia was seen in 19 cases, eleven (58\%) cases were cervical type, five patients had (26\%) blepharospasm, and three (16\%) patients had segmental (LIMBES) dystonia as shown in Table 5.

\section{Discussion}

Dystonia is rare neurological disorder. Many general physicians are unfamiliar with dystonia1 [20]-[22]; they may often confuse it with spasticity or rigidity and sometimes may even mistakenly attribute it to psychogenic causes [23] [24]. Patients with dystonia often consult several physicians before the correct diagnosis is made. Some examples of misdiagnoses include those of cerebral palsy in a child with genetically determined doparesponsive dystonia, also misdiagnosis of dry eyes in a patient with blepharospasm, and cervical muscle strain in a patient with cervical dystonia. Given the recent advances concerning causes and treatment of dystonia, this disorder should be more widely and accurately recognized [25] [26].

Additionally the lack of validated clinical criteria and the absence of a diagnostic test or biomarker make undiagnosis and misdiagnosis of major problems in epidemiological investigations [2].

Primary (idiopathic) dystonia involving an isolated clinical sign of dystonia without any identifiable exogenous cause or other inherited or degenerative diseases, other types of non-primary forms in which dystonia plus is characterized by dystonia in combination with other movement disorders, for example, myoclonus or Parkinsonism. Paroxysmal dystonia is characterized by brief episodes of dystonia with normalcy in between. Primary dystonia and dystonia plus, whether sporadic or familial, are thought to be of genetic origin in most cases [26]-[29].

The present study showed a higher female involvement (68\%) than male and this result was similar to the result shown in European collaborative study (Epidemiological Study of Dystonia in Europe [ESDE]) which was a large study recruiting 957 cases of primary dystonia from Europe [27]. In contrast of that the study of Jowi Jo et al. showed a higher male predilection [30].

The present study showed that Focal dystonia was seen in 19 (86.4\%) and generalized in (13.6\%), which was in approximate to the result of Greene's study [29], which showed that focal dystonia was 10 times more common than generalized dystonia.

Cervical dystonia was seen in (58\%) of the present study patients and female formed 64\%, this result is in accordance with the result of GREEN etal study which report Torticollis in females more than in males [29].

The present study showed Blepharospasm in 5 patients (26\%) with mean age is 43.8 years old and median age of 48 years old. All 5 cases were females, this result is similar to that of study of Green et al. Blepharospasm is 
Table 3. Age group at time of diagnosis.

\begin{tabular}{ccccc}
\hline Age group & Male & Female & Total & Percentage \\
\hline $0-5$ & 1 & 2 & 3 & $14 \%$ \\
$6-10$ & 1 & 1 & 2 & $9.5 \%$ \\
$11-15$ & 1 & 3 & 4 & $18 \%$ \\
$16-20$ & 0 & 0 & 0 & $22 \%$ \\
$21-25$ & 1 & 4 & 5 & $0 \%$ \\
$26-30$ & 0 & 0 & 0 & $5 \%$ \\
$31-35$ & 0 & 1 & 1 & $0 \%$ \\
$36-40$ & 0 & 0 & 0 & $9.5 \%$ \\
$41-45$ & 1 & 1 & 2 & $22 \%$ \\
$>45$ & 2 & 3 & 5 & $100 \%$ \\
\hline
\end{tabular}

Table 4. Time interval between onset of symptoms and diagnosis.

\begin{tabular}{ccccc}
\hline Time (years) & Male & Female & Numbers & Percentages \\
\hline $0-1$ & 2 & 6 & 8 & $36.5 \%$ \\
$>1-3$ & 1 & 3 & 4 & $18 \%$ \\
$>3-5$ & 1 & 1 & 2 & $9 \%$ \\
$>5$ & 3 & 5 & 8 & $36.5 \%$ \\
Total & 7 & 15 & 22 & $100 \%$ \\
\hline
\end{tabular}

Table 5. Type of focal dystonia.

\begin{tabular}{ccccc}
\hline Type of focal dystonia & Male & Female & Numbers & Percentages \\
\hline Cervical & 4 & 7 & 11 & $58 \%$ \\
blepharospasm & 2 & 3 & 5 & $26 \%$ \\
Segmental & 1 & 2 & 3 & $16 \%$ \\
Total & 7 & 12 & 19 & $100 \%$ \\
\hline
\end{tabular}

the most common cranial dystonia, causing an increased blink frequency, forced eye closure, or difficulty opening the eyes [29]. Symptoms are typically aggravated by bright light, reading, or driving, and they can be severe enough to cause functional blindness. In the present study, Segmental (limb) dystonia were seen in 3 (16\%) cases, two cases are upper limb dystonia. Dystonia involving the arm were more frequently than the leg. 2 cases are early onset and involved lower limb with age of onset of 11 and 12 years old.

In present study early onset dystonia were reported in 14 patients (64\%), and late onset dystonia in 8 (36\%) of dystonic patients, which seemed to be non significant statically, (p value is 0.07); the above result was similar to that of the study of Jowi Jo et al. [30].

Classification according to the age at onset is important because when the disease begins in childhood or young adulthood, it usually progresses from focal limb dystonia to the severe generalized form, whereas dystonia that begins after about the age of 25 years old usually involves craniocervical muscles which always remains localized or segmental, and is usually not progressive [31] [32].

Late onset diagnosis above 1 year old was seen in (64.5\%) cases, this reflects the fact that clinician may not 
recognize it even the patient seek medical help or patient themselves ignore their symptom until their activities of daily living are interfered with. Therefore we need to heighten disease awareness among clinicians and patients.

Two cases in the present study were DOPA responsive dystonia and were treated by levodopa [33]. Their ages at onset were 7 years old and 2 years old.

No gene analysis is done in our study as it is not available in our hospital. This rapidly evolving group of genetically determined dystonia has led to the increasing use of genetic counseling in families with these disorders [34].

We do not use the neurophysiological tests as it is not routinely recommended for the diagnosis or classification of dystonia; however, neurophysiologic abnormalities typical of dystonia are used in cases where the clinical features are insufficient to the diagnosis [35].

\section{Recommendations and Conclusions}

Dystonia is rare movement disorder and is more common in female. The primary focal dystonia is more common than generalized type and the cervical dystonia is the commonest type of primary dystonia.

Late onset diagnosis was more common than early diagnosis because of poor awareness of the problem by family physician.

\section{References}

[1] Bressman, S.B. (2004) Dystonia Genotypes, Phenotypes, and Classification. Advances in Neurology, 94, 101-107.

[2] Ozelius, L.J., Hewett, J.W., Page, C.E., Bressman, S.B., Kramer, P.L., Shalish, C., et al. (1998) The Gene (DYT1) for Early-Onset Torsion Dystonia Encodes a Novel Protein Related to the Clp Protease/Heat Shock Family. Advances in Neurology, 78, 93-105.

[3] Furukama, Y., Shimadzu, M., Rajput, A.H., Shimuzu, Y., Tagawa, T., Mori, H., et al. (1996) GTP-Cyclohydrolase 1 Gene Mutationsin Hereditary Progressive and Dopa-Responsive Dystonia. Annals of Neurology, 39, 609-617. http://dx.doi.org/10.1002/ana.410390510

[4] Mink, J.W. (2003) The Basal Ganglia and Involuntary Movements: Impaired Inhibition of Competing Motor Patterns. Archives of neurology, 60, 1365-1368. http://dx.doi.org/10.1001/archneur.60.10.1365

[5] Garraux, G., Bauer, A., Hanakawa, T., Wu, T., Kansaku, K. and Hallett, M. (2004) Changes in Brainanatomy in Focal Hand Dystonia. Annals of Neurology, 55, 736-739. http://dx.doi.org/10.1002/ana.20113

[6] Tempel, L.W. and Perlmutter, J.S. (1990) Abnormal Vibration-Induced Cerebral Blood Flow Responses in Idiopathic Dystonia. Brain, 113, 691-707. http://dx.doi.org/10.1093/brain/113.3.691

[7] Eidelberg, D., Moeller, J.R., Antonini, A., Kazumata, K., Nakamura, T., Dhawan, V., et al. (1998) Functional Brain Networks in dyt1dystonia. Annals of Neurology, 44, 303-312. http://dx.doi.org/10.1002/ana.410440304

[8] Albanese, A., Barnes, M.P., Bhatia, K.P., Fernandez-Alvarez, E., Filippini, G., Gasser, T., et al. (2006) Asystematic Review on the Diagnosis and Treatment of Primary (Idiopathic) Dystonia and Dystonia Plus Syndromes: Report of an EFNS/MDS-ES Task Force. European Journal of Neurology, 13, 433-444. http://dx.doi.org/10.1111/j.1468-1331.2006.01537.x

[9] Hallett, M. (1998) The Neurophysiology of Dystonia. Archives of Neurology, 55, 601-603. http://dx.doi.org/10.1001/archneur.55.5.601

[10] Nemeth, A.H., Nolte, D., Dunne, E., Niemann, S., Kostrzewa, M., Peters, U., et al. (1999) Refined Linkage Disequilibrium and Physical Mapping of the Gene Locus for X-Linked Dystonia-Parkinsonism (DYT3). Genomics, 60, 320-329. http://dx.doi.org/10.1006/geno.1999.5929

[11] Kramer, P.L., Mineta, M., Klein, C., et al. (1999) Rapid-Onset Dystonia-Parkinsonism: Linkage to Chromosome 19q13. Annals of Neurology, 46, 176-182. http://dx.doi.org/10.1002/1531-8249(199908)46:2<176::AID-ANA6>3.0.CO;2-2

[12] Ozelius, L.J., Hewett, J.W., Page, C.E., et al. (1997) The Early-Onset Torsion Dystonia Gene (DYT1) Encodes an ATP-Binding Protein. Nature Genetics, 17, 40-48. http://dx.doi.org/10.1038/ng0997-40

[13] Opal, P., Tintner, R., Jankovic, J., et al. (2002) Intrafamilial Phenotypic Variability of the DYT1 Dystonia: From Asymptomatic TOR1A Gene Carrier Status to Dystonic Storm. Movement Disorders, 17, 339-345. http://dx.doi.org/10.1002/mds.10096

[14] Grundmann, K., Laubis-Herrmann, U., Bauer, I., et al. (2003) Frequency and Phenotypic Variability of the GAG Deletion of the DYT1 Gene in an Unselected Group of Patients with Dystonia. Archives of Neurology, 60, 1266-1270. 
http://dx.doi.org/10.1001/archneur.60.9.1266

[15] Gasser, T., Windgassen, K., Bereznai, B., Kabus, C. and Ludolph, A.C. (1998) Phenotypic Expression of the DYT1 Mutation: A Family with Writer's Cramp of Juvenile Onset. Annals of Neurology, 44, 126-128. http://dx.doi.org/10.1002/ana.410440119

[16] Bressman, S.B., Sabatti, C., Raymond, D., et al. (2000) The DYT1 Phenotype and Guidelines for Diagnostic Testing. Neurology, 54, 1746-1752. http://dx.doi.org/10.1212/WNL.54.9.1746

[17] de Carvalho, P.M. and Ozelius, L.J. (2002) Classification and Genetics of Dystonia. Lancet Neurology, 1, $316-325$. http://dx.doi.org/10.1016/S1474-4422(02)00137-0

[18] Valente, E.M., Warner, T.T., Jarman, P.R., Mathen, D., Fletcher, N.A., Marsden, C.D., et al. (1998) The Role of DYT1 in Primarytorsion Dystonia in Europe. Brain, 121, 2335-2339. http://dx.doi.org/10.1093/brain/121.12.2335

[19] Ropper, A.H. and Brow, R.H. (2005) Adams and Victor's Principle of Neurology. Eighth Edition, McGraw-Hill, New York.

[20] Bressman, S.B., Raymond, D., Wendt, K., et al. (2002) Diagnostic Criteria for Dystoniain DYT1 Families. Neurology, 59, 1780-1782. http://dx.doi.org/10.1212/01.WNL.0000035630.12515.E0

[21] Fahn, S., Marsden, C.D. and Calne, D.B. (1987) Classification and Investigation of Dystonia. In: Marsden, C.D. and Fahn, S., Eds., Movement Disorders, Butterworths, London, 332-358.

[22] Defazio, G., Abbruzzese, G., Livrea, P., et al. (2005) Epidemiology of Primary Dystonia. Lancet Neurology, 3, 673678.

Jowi, J.O. and Musoke, S.S. (2005) Dystonia: Case Series of Twenty Two Patients. East African Medical Journal, 82, 463-467.

[23] Greene, P., Kang, U.J. and Fahn, S. (1995) Spread of Symptoms in Idiopathic Torsion Dystonia. Movement Disorders, 10, 143-152. http://dx.doi.org/10.1002/mds.870100204

[24] Svetel, M., Ivanovic, N., Marinkovic, J., Jovic, J., Dragasevic, N. and Kostic, V.S. (2004) Characteristics of Dystonic Movements in Primary and Symptomatic Dystonias. Journal of Neurology, Neurosurgery and Psychiatry, 75, 329-330. http://dx.doi.org/10.1136/jnnp.2003.017632

[25] De Carvalho Aguiar, P.M. and Ozelius, L.J. (2002) Classification and Genetics of Dystonia. Lancet Neurology, 1, 316325. http://dx.doi.org/10.1016/S1474-4422(02)00137-0

[26] Nemeth, A.H. (2002) The Genetics of Primary Dystonias and Related Disorders. Brain, 125, 695-721. http://dx.doi.org/10.1093/brain/awf090

[27] Rutledge, J.N., Hilal, S.K., Silver, A.J., Defendini, R. and Fahn, S. (1988) Magnetic Resonance Imaging of Dystonic States. Advances in Neurology, 50, 265-275.

[28] Doheny. D.O., de Leon, D. and Raymond, D. (2004) Genetic Testing and Genetic Counseling. In: Brin, M.F., Comella, C.L. and Jankovic, J., Eds., Dystonia: Etiology, Clinical Features, and Treatment, Lippincott Williams \& Wilkins, Philadelphia, 23-32.

[29] Greene, P.E. and Bressman, S. (1998) Exteroceptive and Interoceptive Stimuli in Dystonia. Movement Disorders, 13, 549-551. http://dx.doi.org/10.1002/mds.870130329

[30] Jowi, J.O. and Musoke, S.S. (2005) Dystonia: Case Series of Twenty Two Patients. East African Medical Journal, 82, 463-467.

[31] Lee, H.Y., Xu, Y., Huang, Y., Ahn, A.H., et al. (2004) The Gene for Paroxysmal Non-Kinesigenic Dyskinesia Encodes an Enzyme in a Stress Response Pathway. Human Molecular Genetics, 13, 3161-3170. http://dx.doi.org/10.1093/hmg/ddh330

[32] Quinn, N.P. (1996) Essential Myoclonus and Myoclonic Dystonia. Movement Disorders, 11, 119-124. http://dx.doi.org/10.1002/mds.870110202

[33] Aramideh, M., Ongerboer de Visser, B.W., Koelmann, J.H.T.M. and Speelman, J.D. (1995) Motor Persistence of Orbicularis Oculi Muscle in Eyelid-Opening Disorders. Neurology, 45, 897-902. http://dx.doi.org/10.1212/WNL.45.5.897

[34] Albanese, A. (2003) The Clinical Expression of Primary Dystonia. Journal of Neurology, 250, 1145-1151. http://dx.doi.org/10.1007/s00415-003-0236-8

[35] Hughes, M. and McLellan, D.L. (1985) Increased Co-Activation of the Upper Limb Muscles in Writer's Cramp. Journal of Neurology, Neurosurgery and Psychiatry, 48, 782-787. http://dx.doi.org/10.1136/jnnp.48.8.782 